\title{
PRINCIPALES MODIFICACIONES INTRODUCIDAS AL PROCESO DE SUCESIÓN POR EL CÓDIGO GENERAL DEL PROCESO*
}

Jesael Antonio Giraldo Castaño**

\section{RESUMEN}

El Derecho Sustancial Sucesoral es una de las ramas del Derecho Civil que menos modificaciones de fondo ha tenido en Colombia, pese a que responde a criterios políticos, económicos y sociales mediales, que hoy no tienen vigencia y que condujeron a la rigidez de la disposición patrimonial testamentaria. Lo anterior hace prácticamente nugatoria la institución del testamento o impide de manera total la distribución del patrimonio en vida entre los herederos. De ahí, que una de las reformas más novedosas y profundas que trae el Código General del Proceso, ya declarada exequible por la Corte Constitucional, es la posibilidad de efectuar la partición de los bienes en vida entre los herederos, como negocio jurídico constitutivo y traslaticio, con el lleno de los requisitos previstos en él. Igualmente, se regulan las oposiciones a la apertura del testamento, se adaptan los procedimientos a la oralidad, se superan dificultades actualmente existentes con las medidas cautelares y se hace una reglamentación más acorde con las normas generales de las cautelas. Además, para privilegiar los principios de oralidad,

Recibido: Septiembre 15 de 2014 - Aceptado: junio 10 de 2015

* Artículo inédito.

** Abogado de la Universidad Libre, especialista en Filosofía del Derecho y en Derecho Procesal de la Universidad Libre, especialista en Derecho Civil y Biotecnología de la Universidad de Salamanca, Doctor en Derecho Civil de la Universidad de Zaragoza (España). Ex - Magistrado del Consejo Superior de la Judicatura, docente universitario. Es miembro del Instituto Colombiano de Derecho Procesal y de la Comisión Redactora y Revisora del Código General del Proceso. 
inmediación y concentración, tan abrigados por el código, se realiza en audiencia todo lo atinente a la confección, objeciones, trámite de estas, práctica de pruebas, sustentación de dictámenes periciales, decisión de objeciones, aprobación, decreto de la partición y nombramiento de partidor.

De otro lado, la comparecencia al proceso de sucesión se hace más coercitiva en la medida en que el silencio de los herederos, una vez notificados de la apertura del proceso, conduce a la pérdida de sus derechos herenciales, con lo cual se privilegia la economía procesal, porque se impide su reclamación en proceso declarativo separado. Por consiguiente, se deduce que las diversas reformas en el proceso de sucesión rendirán abundantes frutos.

Palabras clave: proceso de sucesión, reforma, oposiciones, silencio.

\section{Abstract}

The substantial probate right is one of the branches of civil right that had received fewer substantive modifications in Colombia, despite that it responds to political, economic and social criteria, which currently do not have validity and led to the rigidity of the probate patrimonial arrangement. This makes practically nugatory the institution of testament or prevents in a total way the distribution of assets among the heirs alive. Hence, that one of the newest and deeper reforms that brings the General Code of Procedure, declared exequible by the Constitutional Court, is the possibility of the partition of live properties among heirs, as constituting juridical and traslaticio business, with the full requirements under him. Similarly, opposition to the opening of the will are regulated, the procedures to orality are adapted, existing difficulties with the precautionary measures are overcome and regulations more in line with the general rules of caution are made. Moreover, to favor the principles of orality, immediacy and concentration, so sheltered by the Code, it takes place in audience everything related to the making, objections, processing, tests practice, expert opinions sustain, objections decision, approval, decree of partition and appointment of the divider.

On the other hand, the appearance succession process becomes more coercive to the extent to the silence of the heirs, once notified of the opening of the process, leading to the loss of their inheritance rights, which favors the procedural economy, because their claim of separately declarative process is prevented. Therefore, it follows that the various reforms in the succession process will yield abundant fruit.

Keywords: succession process, reform, oppositions, silence. 


\section{CRISIS Y PÉRDIDA DE LA FUNCIÓN ORIGINAL DE LA SUCESIÓN EN LAS LEGISLACIONES DE ORIGEN OCCIDENTAL.}

Uno de los aspectos que mayor preocupación ha suscitado a la humanidad es su condición de mortalidad. Su tiempo finito en la existencia. Como bien lo afirma Cees Nooteboom ${ }^{1}$ en su ingeniosa obra En Las Montañas de $H o l a n d a^{2}$, no hay felicidad perfecta si estamos seguros que nos espera la vejez, la enfermedad y la muerte. A quien todo esto lo tenga sin cuidado, ha logrado la perfecta felicidad.

Un tema unido indisolublemente a esta preocupación del ser humano por la muerte es lo referente a sus bienes materiales y la titularidad de los mismos. Desde que surgió la civilización ha sido una preocupación constante del ser humano, determinar la forma cómo sus bienes pasarán a sus sucesores.

Justo por ello los romanos idearon la adopción para quienes no podían tener hijos, pues, además de la transferencia de los bienes, la descendencia debía continuar con los cultos religiosos familiares.

Pero hoy es una conclusión concurrente en los países que tienen los ordenamientos pertenecientes a la tradición jurídica occidental, la crisis y la pérdida de la función de la disciplina sobre las sucesiones por causa de muerte.

Este proceso ya no tiene una función política como en el derecho feudal, en el cual se establecía un nexo entre la sucesión y las reglas de la organización política institucional a través de las instituciones del mayorazgo y el fideicomiso ${ }^{4}$,

$1 \quad$ Novelista y poeta de los Países Bajos, 1933. Citado por ZOPINI, Andrea, "Las sucesiones en el Derecho Comparado". Sucesiones y Herencia. Colección Tendencias Contemporáneas del Derecho, No. 15. Editores Académicos, 2013, p. 69 y ss.

2 NOOTEBOOM, Cees. En Las Montañas de Holanda. Editorial Siruela, 2009. Colección Nuevos Tiempos, traducida por Felipe Lorda i Alaiz.

3 El mayorazgo fue regulado mediante las Leyes de Toro en 1505, cuyo fin principal era evitar el fraccionamiento de las herencias para mantener el poder económico de las familias. Tampoco se permitía su enajenación. Esto fue la culminación de una serie de privilegios concedidos a los nobles castellanos por Enrique IV de Castilla. El fundador del mayorazgo limitaba la transmisión del dominio de ciertos bienes y derechos sujetándolos a un orden sucesorio determinado e irreformable que los hacía inalienables e indivisibles, de suerte que el titular solo tenía el uso y goce de los bienes que comprendía. Estuvo vigente en España hasta 1820.

4 La fiducia o fidecommissum en el Derecho Romano era una institución creada en el marco del derecho sucesorio, basada en la confianza, mediante la cual el fideicomitente encargaba al fiduciario la entrega de un patrimonio hereditario concreto a una persona, el fideicomisario. Al comienzo era informal y revocable. 
o en el sistema político de la sociedad burguesa, en donde la representación democrática dependía del patrimonio del votante. Tampoco tiene una función meramente asistencial en los estados sociales de derecho, porque en estos es el Estado el que el que provee la asistencia (Estado bienestar) ${ }^{5}$.

Ya no sirve de protección del menor como en el derecho medieval, porque el prolongamiento de la vida ha determinado un salto generacional en la transmisión hereditaria. La vida media de los hombres está lejos de ser la que era cuando se expidió el Código Francés en 1804, en donde los padres morían y quedaban los hijos menores. Los estudios estadísticos demográficos muestran que hoy los padres mueren cuando los hijos son mayores y han ingresado al mundo laboral.

De ahí que se abra paso la sucesión anticipada para imputarles una futura herencia a los hijos y reservarle una fuente de sostenimiento para vivir.

La tendencia es a la supresión o debilitamiento de la legítima, como ocurre hoy en el derecho chino, en el que el juez puede adjudicar el patrimonio en la sucesión intestada a las personas o instituciones que hayan protegido al causante; o en el de Estados Unidos, donde los hijos no tienen derecho a la legítima, salvo en Luisiana para menores y para los discapacitados. Hay una fuerte tendencia a que los derechos sucesorios se transmitan según el comportamiento de los parientes y al fortalecimiento de la sucesión testada y de los pactos sucesorales entre vivos ${ }^{6}$.

Una de las legislaciones más modernas en materia sucesoral es la Ley 10 del 10 de julio de 2008 de Cataluña, donde se hizo una transformación profunda al régimen sucesoral.

En Colombia, por la rigidez del sistema de las asignaciones forzosas, la sucesión testada está prácticamente en desuso, es excepcional encontrar una sucesión testada, de ahí que la extensísima regulación legal sobre la materia tenga uso excepcional. También puede tener como causa lo que anota Cees Nooteboom: las personas que menos piensan en la muerte son más felices. Colombia ocupa un lugar de privilegio entre los países más felices en el mundo, seguramente, porque sus habitantes poco se preocupan por la suerte de sus días o si lo hacen no se animan a testar por el poco espacio que tiene su libertad de disposición de los bienes.

Además, una de las regulaciones civiles que menos modificaciones ha tenido desde la primera vigencia del Código Civil el 26 de mayo de 1873 es la de sucesiones, que escasamente se modificó para reconocerle derechos en el primer

$5 \quad$ Op. cit. Novelista y Poeta de los Países Bajos. Sucesiones y Herencia.

6 Ibídem. 
orden sucesoral al hijo natural, con la leyes 45 de 1936 y 29 de 1982, y el reconocimiento por la jurisprudencia de la Corte Constitucional de derechos hereditarios y porción conyugal a los compañeros permanentes de distinto o del mismo sexo.

Debe modificarse el régimen sucesoral para privilegiar la voluntad del causante en la disposición de sus bienes y desformalizar el testamento para que sea más fácil su otorgamiento y menos compleja su eficacia. Es lo más acorde con una sociedad liberal y el sistema de libre mercado.

\section{MODIFICACIONES IMPORTANTES QUE INTRODUJO EL CGP EN LA SUCESIÓN.}

El proceso de sucesión sufrió importantes reformas, desde las disposiciones sobre medidas preparatorias hasta la entrega de los bienes adjudicados, aunque, en términos generales, conserva su estructura. Quizás las reformas más sobresalientes se encuentran en la partición patrimonial en vida, coercibilidad a los herederos para la comparecencia al proceso, la confección del inventario y avalúos y las objeciones al mismo.

\section{PARTICIÓN DEL PATRIMONIO EN VIDA. PARÁGRAFO DEL ARTÍCULO 487 DEL CGP.}

Una de las grandes innovaciones en materia sucesoral que introduce el CGP en el Derecho Sustancial Sucesoral es la partición patrimonial en vida, vigente desde el $1^{\circ}$ de octubre del año 2012, una institución jurídica novedosa y conveniente que no estaba prevista en la ley y que consiste en que una persona podrá adjudicar todo o parte de sus bienes, con o sin reserva de usufructo o administración, por escritura pública, previa licencia judicial, siempre que se respeten las asignaciones forzosas, los derechos de terceros y los gananciales. Para este último caso, se requiere el consentimiento del cónyuge o compañero.

Con todo, los herederos, el cónyuge o compañero permanente y los terceros que acrediten un interés legítimo, podrán solicitar su rescisión dentro de los dos años siguientes a la fecha en que tuvieron o debieron tener conocimiento de la partición.

Debe resaltarse que no se trata de una rescisión por lesión enorme, es más bien una rescisión especial por vulnerar derechos de otros interesados en la partición.

Se señala, así mismo, que esta partición no requiere del trámite de proceso de sucesión.

Según el profesor Pedro Lafont, la disposición comentada es idéntica al artículo 1401 del Proyecto de Código Civil de 1980 que dice: "Toda persona 
podrá mediante escritura pública adjudicar sus bienes o parte de ellos entre sus legitimarios respetando las legítimas, los gananciales y los derechos de terceros. Si hubiere gananciales, será necesario el consentimiento del otro cónyuge. El disponente podrá reservarse el usufructo o la administración de determinados bienes"7. En verdad, comparadas las dos normas, resultan prácticamente idénticas.

En algunos países, como anotan los autores, esta partición patrimonial en vida, que en Argentina se denomina partición por donación, tiene una reglamentación amplia desde el Código Civil original, cuya aplicación ha resultado controversial, como lo anota el tratadista José Luis Pérez Lasala ${ }^{8}$.

Dice el autor citado, que la partición por donación tiene una naturaleza híbrida, pues sin dejar de ser donación produce los efectos de una partición hereditaria, y agrega que no tiene, por tanto, carácter declarativo, una vez realizada y aceptada produce efectos traslaticios inmediatos. Solo pueden hacerla los ascendientes. La omisión de descendientes o el nacimiento de otros anulan la partición. Se consagran además las acciones de reducción y de rescisión que no pueden ejercerse sino después de la muerte del donante. Igualmente, sostiene que esta figura es poco usada, ya que las personas acuden con mayor frecuencia a la donación, además, que por inconveniente fue derogada en Italia en el Código Civil de 1942 y por lo mismo se aboga en Argentina.

En Colombia no se hizo una regulación exhaustiva y ello conducirá a que surjan múltiples controversias. Aquí no se dice nada sobre lo que sucede si surgen nuevos asignatarios o de la forma en que se debe distribuir la herencia si el causante deja otros bienes y hay nuevos asignatarios. De igual forma, no se ha tratado el tema de la transferencia de los bienes, si esta se hace a título de donación o si habría que hacer las acumulaciones; tampoco se reguló una acción de reducción de cuotas, sino que se aplica directamente la rescisión, que echa por tierra la partición. Finalmente, no se dijo nada sobre cómo se protegerían los derechos de los acreedores. En Argentina los donatarios deben responder por las deudas.

Sin embargo, no hay duda de que la partición anticipada es negocio jurídico traslaticio de naturaleza mixta, esto es, de orden público, en cuanto a sus bases, elementos y contenido, y, de orden privado, en cuanto exige el acuerdo de voluntades del disponente y del beneficiario. Como la misma norma lo establece, esta puede ir acompañada de otros pactos como la reserva de usufructo o

7 LAFONT PIANETTA, Pedro. Derecho de Sucesiones. Tomo II. Librería Ediciones El profesional, 2013. pp. 587 y ss.

8 PÉREZ LASARA, José Luis. Curso de Derecho Sucesorio. Ediciones Depalma, 1989. pp. 355 y ss. 
administración, fideicomiso, renta vitalicia, disolución y liquidación de sociedad conyugal o patrimonial, entre otros ${ }^{9}$. De lo anterior se deduce que el orden privado de la partición tiene que ver con sus efectos en vida.

La causa de la disposición de la partición anticipada no es la muerte; luego, el modo de adquirir no es la sucesión, sino la tradición antecedida de un título que no es otro que la ley misma, aunque se sirva del régimen sucesoral por tratarse de una institución compleja; y la causa de la adquisición no es onerosa sino gratuita. Además, distinto a lo que ocurre con la partición sucesoral, su naturaleza no es declarativa (CC, art. 1401), sino constitutiva y traslaticia, en tanto que el derecho y dominio surgen con el negocio jurídico partitivo. Se diferencia de la donación en que esta es rescindible, en caso de exceso, y la partición anticipada solo lo es en el caso especial previsto en el parágrafo del artículo 487 del CGP.

Como es negocio jurídico de disposición con efectos en vida, de acuerdo con el artículo 1293 del CC, solo los que tienen la libre administración de sus bienes pueden disponer en vida de su patrimonio, de manera que quedan excluidos los incapaces. Ahora bien, de acuerdo con la regulación actual de la inhabilitación judicial por la Ley 1306 de 2009, todo indica que el inhábil negocial no puede hacer partición judicial en vida, porque solo es capaz negocial para disponer de los bienes que el juez le señale en la parte resolutiva de la sentencia de inhabilitación con miras a proteger su patrimonio, ya que, mal podría disponer de todo o parte de su patrimonio en vida. En cambio, los beneficiarios solo deben tener capacidad de goce o jurídica, esto es, ser personas.

Ahora bien, en virtud de la naturaleza compleja de la partición en vida, los asignatarios forzosos que surjan con posterioridad a la partición pueden ejercer el derecho de colación, consistente en la facultad de solicitar la acumulación imaginaria de las donaciones realizadas por el disponente y la restitución por parte de los asignatarios de lo que se les haya adjudicado en exceso $(\mathrm{CC}$, arts. $1242,1245$ y 1282$)^{10}$.

En fin, serán la jurisprudencia y la doctrina las que desarrollen esta novedosa institución.

Desde que se propuso la norma, en la Comisión se dudó sobre su constitucionalidad en virtud de que eventualmente rompía la unidad de materia, por cuanto se regulaba un asunto de derecho sustancial en código de procedimiento. Sin embargo, se concluyó que no, toda vez que también contemplaba un trámite para la realización de la partición.

Evidentemente la norma fue demandada por violación de la unidad de materia y por violación al derecho a la igualdad de los asignatarios que pudieran surgir

\footnotetext{
$9 \quad$ Ver LAFONT. Ob. cit. pp. 596 y ss.

$10 \quad$ Ibídem. pp. 588 y ss.
} 
después de la partición, pero la Corte Constitucional en Sentencia C-683 del 10 de septiembre de 2014, con ponencia del doctor Mauricio González Cuervo, declaró que la norma es exequible. Sobre el particular dijo la Corte:

La Corte consideró, frente al primer cargo, que la disposición acusada es exequible porque guarda conexidad temática, sistémica y teleológica con el Código General del Proceso. Respecto al segundo cargo, esta Corporación estimó que la figura de la partición del patrimonio en vida contenida en el parágrafo del artículo 487 del Código General del Proceso, no desconoce el derecho a la igualdad de los hijos que no hayan consolidado su relación paterno filial ni de los futuros terceros interesados que en el momento de la partición no tengan vocación hereditaria ni un derecho reconocido que proteger ya que es el vínculo jurídico o parental el que les otorga la potestad de participar en la misma. En todo caso, la disposición protege los derechos de las personas que demuestren un interés legítimo durante el proceso mediante la licencia judicial y, después de concluida la partición, mediante la solicitud de rescisión que dispone la norma la cual constituye una garantía de los derechos de los interesados.

\section{COMPETENCIA EN EL CÓDIGO GENERAL DEL PROCESO (ARTÍCULO 17 NUMERAL 2, 18 NUMERALES $4^{\circ}, 5^{\circ}$ Y $6^{\circ}$, Y 22 NUMERAL $9^{\circ}$ ).}

En materia de competencia el Código General del Proceso, conserva las normas actuales en el sentido de que conoce en única instancia de los procesos de sucesión de mínima cuantía, y las de menor en primera instancia el juez civil municipal o promiscuo municipal, haya o no juez de familia en lugar donde debe tramitarse la sucesión.

Así mismo, al juez civil municipal o promiscuo municipal en primera instancia se le aumentaron en el artículo 18 dos asuntos que conoce hoy el juez de familia en primera instancia que son:

"5. De las diligencias de apertura y publicación de testamento cerrado, o del otorgado ante cinco (5) testigos, y de la reducción a escrito de testamento verbal, sin perjuicio de la competencia atribuida por la ley a los notarios.

6. De la corrección, sustitución o adición de partidas de estado civil o de nombre o anotación del seudónimo en actas o folios del registro de aquel, sin perjuicio de la competencia atribuida por la ley a los notarios".

En primera instancia conoce el juez de familia del proceso de sucesión de mayor cuantía, y donde no haya juez de familia, conoce el juez civil del circuito.

La segunda instancia de los procesos que conoce en primera el juez civil municipal es realizada por el juez de familia y las salas de familia o salas civil- 
familia (arts. 34 y 32 , num. $1^{\circ}$.) conocen en segunda instancia de los que se tramitan en primera ante los jueces de familia o civiles del circuito.

La competencia atribuida a los jueces civiles donde hay jueces de familia obedece al afán de la comisión por facilitar el acceso a la administración de justicia, dado que el juez municipal es más cercano al ciudadano.

\section{CUANTÍA. ARTíCULO 26 NUMERAL $5^{\circ}$.}

La norma citada establece que la cuantía se determina por el valor de los bienes relictos y el de los inmuebles será el avalúo catastral. No guardó armonía esta norma con el artículo 489, numerales $4^{\circ}$ y $5^{\circ}$, que ordena aportar la demanda, el inventario y los avalúos y ordena que estos contengan los valores de los inmuebles y de los vehículos automotores como lo dispone el artículo 444 del código. Esto es, que el valor de los inmuebles será el avalúo catastral aumentado en un cincuenta por ciento o, en caso de no estar de acuerdo, el que se determine en un dictamen pericial que se acompañará con la demanda. En cuanto al valor de los vehículos automotores, este será el del impuesto de rodamiento o el que aparezca en revistas especializadas (por ejemplo, el de la revista Motor, Fasecolda, etc.).

\section{ALTERACIÓN DE LA COMPETENCIA.}

Prevé el artículo 21 del CPC, que la competencia varía si, una vez aprobado el inventario, el proceso, en lugar de ser de mínima o menor, es de menor o mayor o viceversa. En este caso, el proceso se envía al que resulte competente por el valor de los bienes. Era lo que se conocía como excepción a la perpetuatio jurisdictionis. El artículo 27 del código acabó con esta excepción que traía el 21 del CPC, así, el valor de los bienes, aprobado el inventario, no altera la competencia. Sin embargo, esta norma aún no está vigente como sí lo está el 24, sobre determinación de la competencia.

\section{FUERO DE ATRACCIÓN.}

En el artículo 23 del código, una norma autónoma y no un numeral, como está en el 15 del artículo 23 del CPC, se consagra el fuero de atracción con algunas modificaciones.

El juez competente ya no es el que "conozca del proceso de sucesión", como lo establece el actual artículo 23, numeral 15, del CPC, que dio lugar a que se interpretara que aquel que conociera de los procesos que surgieran con ocasión de la sucesión, sería el juez al que le sería asignado el asunto por reparto. De acuerdo con esta disposición, el juez debe ser el que "tramite el proceso de sucesión", sin necesidad de reparto y siempre que la sucesión sea de mayor cuantía. Esta 
última previsión obedece a que si la sucesión es de mínima o de menor, le corresponde al juez civil municipal, que no es competente para conocer de los procesos declarativos conexos. Igualmente, se dijo de qué procesos conoce el juez de la sucesión y se trasladaron todos los que están hoy relacionados en el artículo 26 de la Ley 446 de 1998, sobre el régimen económico del matrimonio y derechos sucesorales.

Esta norma aún no ha entrado en vigencia.

\section{MEDIDAS PREPARATORIAS EN SUCESIONES TESTADAS.}

\subsection{ArtíCulo 473. APERTURA Y PUbLiCACIÓN JUdicial DEL TESTAMENTO CERRADO EN CASO DE OPOSICIÓN.}

El Código Civil contempla la posibilidad de otorgar testamento cerrado y los requisitos de validez del mismo (arts. 1078 a 1083). Una vez otorgado, se le deja en custodia al notario o al cónsul que lo haya autorizado, hasta que algún interesado, una vez muerto el testador, solicite su apertura. Si alguien que demuestre un interés se opone a la apertura, el notario se abstendrá de practicarla y enviará el testamento al juez competente para conocer del proceso de sucesión y para que ante él se tramite y decida la oposición correspondiente (arts. 59 al 67, Dec. 960/1970). A su vez, el artículo 571 del CPC consagra la forma en que debe tramitarse la oposición.

Con el artículo 473 del CGP, lo único que cambia del trámite es que la citación del opositor ya no se hará mediante telegrama que le haga saber la fecha y hora de la audiencia, sino que la misma se realizará "mediante cualquier medio comunicación expedito, dejando constancia de ello en el expediente, haciéndole saber la fecha y hora de la audiencia”. Igualmente, se suprime la apelación en el efecto diferido contra la providencia mediante la cual se decide la oposición. En lo demás, la disposición se mantiene igual. Se conservan las consecuencias del rechazo o de la admisión de la oposición, consistentes en la publicación del testamento o en la necesidad del trámite del proceso verbal, según el caso.

\subsection{Artículo 474. PUblicación del testamento otorgado ANTE CINCO TESTIGOS.}

El artículo 1077 del CC contempla la posibilidad de otorgar testamento ante cinco testigos, cuando no se otorga ante notario, y el artículo 572 del CPC consagra el trámite de la diligencia para su publicación. 
Lo primero que debe observarse es que la norma citada establece que el competente es el juez del circuito del lugar donde se otorgó. El Decreto 2272 de 1989, con el cual se creó la jurisdicción de familia, en el artículo $5^{\circ}$ numeral $10^{\circ}$, le atribuyó competencia a los jueces de familia para realizar las "diligencias de apertura y publicación de testamento cerrado y de la reducción a escrito de testamento verbal", dejando por fuera la publicación del testamento otorgado ante cinco testigos. El citado artículo 572 se refiere al juez del circuito, entendiendo que era el civil, ya que para la época de la expedición del Código no existía la jurisdicción de familia pero, una vez creada, debió asignarse esta competencia al juez de familia, pero lo olvidó el legislador. Con todo, esa referencia al juez del circuito ha de entenderse como hecha al juez de familia, por cuanto la sucesión y todas las controversias relativas al testamento fueron asignadas al juez de familia, y para la época no había juez de familia.

El CGP, en su artículo 474, dice que la solicitud debe enviarse al juez del lugar donde se otorgó, pero ha de tenerse en cuenta que el artículo 18 , numeral $5^{\circ}$, le asigna esta competencia al juez civil municipal en primera instancia.

En la última parte del artículo 572 del CPC, se dice que si las firmas del testador o los testigos no fueren reconocidas o debidamente abonadas o si de las declaraciones no aparece que dicho acto es el testamento del causante, el juez declarará que el escrito no reviste el carácter de testamento nuncupativo (o público otorgado ante testigos) sin perjuicio de que el asunto se ventile en proceso ordinario. El 474 del CGP cambia el trámite del proceso por el verbal.

\subsection{ARtículo 475. REDUCCIÓN A ESCRITO de TESTAMENTO VERBAL.}

El testamento verbal es un testamento privilegiado al lado del militar y del marítimo. Se otorga en casos de peligro inminente de muerte, ante tres testigos por lo menos, y siempre que no haya modo de otorgar testamento solemne (CC, arts. 1090 a 1097), sin embargo, existe la necesidad de reducirlo a escrito dentro de los 30 días siguientes a la muerte del testador.

Para ello es necesario adelantar el trámite previsto en el artículo 573 del CPC. Este dice que debe acudirse al juez del circuito del lugar donde se otorgó, que ha de entenderse por el juez de familia, porque el Decreto 2272 de 1989 en el artículo $5^{\circ}$, numeral $10^{\circ}$, le asignó esta competencia al juez de familia y el artículo 475 del CGP dice que se acude al juez del lugar donde se otorgó y suprime la expresión juez del circuito, por cuanto la competencia en el CGP es del juez civil municipal en primera instancia (art. 18 numeral $5^{\circ}$ ).

En el numeral $3^{\circ}$ se cambia la expresión "Previamente a la celebración de la audiencia", por "Antes de la celebración de la audiencia" y la expresión: "se 
publicará en un diario de amplia circulación en el lugar y en una radiodifusora local, si la hubiere", por la expresión: "se publicará en la forma prevista para el emplazamiento". En lo demás, la norma se mantiene igual.

\section{MEDIDAS CAUTELARES.}

\subsection{Artículo 476. GUARdA y APOSICIÓN DE SELlos.}

Actualmente el CPC establece en el artículo 575 que en la solicitud de guarda y aposición de sellos se determinarán con precisión los bienes y el lugar donde se encuentren. La verdad es que resulta muy difícil determinar los bienes muebles y documentos del difunto, cuando precisamente la medida cautelar lo que busca es la protección de ellos; de ahí que el artículo 476 del CGP diga que "se indicará el lugar donde se encuentren los bienes", sin exigir que se determinen con precisión.

De otra parte, el artículo 575 del CPC establece que las joyas se depositarán en un establecimiento bancario y el CGP, en el artículo 477, cambia la palabra "bancario" por especializado, ya que actualmente existen establecimientos especializados en la custodia de esa clase de bienes.

Así mismo en el numeral 8º el artículo 477 del CGP hace la precisión de que si se presenta oposición al secuestro, para resolverla se aplicará lo dispuesto en los numerales $1^{\circ}$ y $2^{\circ}$ del artículo 596, el cual regula las oposiciones al secuestro $\mathrm{y}$, obviamente, suprime la remisión que hoy se hace al parágrafo $1^{\circ} \mathrm{y}$ el inciso primero del parágrafo $2^{\circ}$ del artículo 686 del CPC, que es el que actualmente regula las oposiciones al secuestro

\subsection{ARTículo 478. Terminación DE LA GUARDA.}

El artículo 577 del CPC consagra que si dentro de los diez días siguientes a la diligencia no se hubiere promovido el proceso de sucesión, el juez declarará terminadas las anteriores medidas (las de guarda y aposición de sellos) y decretará el secuestro provisional de los bienes, el cual se regirá por lo dispuesto en el artículo 579. Iniciado el proceso, se levantarán dichas medidas y se entregarán los bienes a quienes tengan derecho a administrarlos.

El CGP, en el artículo 478, reduce el contenido de la norma, para indicar que si en el plazo de diez (10) días no se inicia el proceso, "el juez levantará las anteriores medidas, salvo que se haya solicitado el secuestro de los mismos". De suerte que si se pide el secuestro, dichas medidas quedan sin efecto, de pleno derecho, dado que los bienes se le entregan al secuestre.

El artículo 479 del CGP prescribe que las autoridades de policía solamente prueben practicar las medidas de aposición de sellos y, concluida la diligencia, 
deben remitir lo actuado al juez que fuere competente para tramitar el proceso de sucesión, la norma no trae variación alguna frente a lo dispuesto en el artículo 578 del CPC que reemplaza.

\subsection{MEDIDAS CAUTELARES DE EMBARGO Y SECUESTRO PROVISIONAL.}

La verdad es que las medidas cautelares de embargo y secuestro provisional no fueron claramente reguladas en el Código de Procedimiento Civil y han generado muchas controversias.

El artículo 579 del CPC establece que se puede pedir el embargo y secuestro provisional de los bienes que estén en cabeza del causante y que estén sujetos a registro, y solamente el embargo de los que estén en cabeza del cónyuge sobreviviente y que formen parte del haber de la sociedad conyugal. Así mismo, que si los bienes muebles no pueden guardarse bajo llave y sello, se decretará también el secuestro.

Lo que se pretende es que los bienes del causante no solo no puedan enajenarse, lo cual resulta difícil, como quiera que el titular ha desaparecido, sino que puedan ser administrados por el secuestre mientras se inicia el proceso de sucesión y sean entregados a quien tenga derecho a la administración, que puede ser el cónyuge, los herederos o el albacea con tenencia de bienes. En cambio, los bienes sujetos a registro que están en cabeza del cónyuge supérstite solo pueden ser embargados, pues este conserva su tenencia o posesión.

Este embargo y secuestro provisional puede pedirse por cualquier persona que tenga interés desde antes de la presentación de la demanda de sucesión y hasta antes de la aprobación del inventario y termina en los casos previstos en el artículo 580 del CPC, esto es, cuando deban entregarse los bienes al curador de la herencia yacente, al albacea con tenencia de bienes, a los herederos o al cónyuge supérstite, según el caso.

Hay situaciones complejas que no están previstas, como el hecho de que no se inicie el proceso de sucesión o que el juez que practica la diligencia no sea el competente para el trámite de la sucesión.

Así mismo, se prevé el secuestro definitivo, desde la iniciación del proceso de sucesión y hasta la culminación del mismo, pero solo en el caso previsto en el artículo 595 numeral $2^{\circ}$ del CPC, vale decir, "en caso de desacuerdo entre los herederos, o entre estos y el cónyuge sobreviviente, en torno a la administración que adelanten".

Bien puede ocurrir que se haya decretado el embargo y secuestro provisional, o que se hayan practicado medidas cautelares de guarda y aposición de sellos, y que se solicite la transformación de aquella medida en secuestro definitivo o que 
se haya pedido el secuestro definitivo de los bienes que fueron objeto de guarda y aposición de sellos, caso en cual procede dicha transformación.

Pero obsérvese cómo el embargo no está previsto sino hasta la aprobación del inventario y, de aquí en adelante, solo se prevé el secuestro definitivo, para lo cual no es necesario pedir el embargo, en los supuestos del artículo 595 del CPC o 496 del CGP.

En el proceso de sucesión no es necesario prestar caución para el decreto y práctica de ninguna de las medidas cautelares mencionadas.

El Código General establece en el artículo 480 que, aún antes de la apertura del proceso de sucesión y hasta antes de proferirse la sentencia aprobatoria de la partición, se puede pedir el embargo y secuestro por cualquiera de las personas de que trata el artículo 1312 del CC y el compañero permanente del causante, que acredite siquiera sumariamente interés para pedir el embargo y secuestro de los bienes del causante, sean propios o sociales, y de los que forman parte del haber de la sociedad conyugal o patrimonial que estén en cabeza del cónyuge o del compañero permanente del causante.

Se precisa qué personas pueden solicitar dichas medidas, se señala aquellas que relaciona el artículo 1312 del CC, que son las que pueden acudir a la confección del inventario (CGP art. 501), pero que deben demostrar sumariamente el interés en el decreto y práctica de las medidas.

Se embargan y secuestran no solo los bienes sujetos a registro sino todos los propios del causante y los sociales de este y del cónyuge supérstite.

Se mejora la redacción de la norma prevista hoy en el numeral $4^{\circ}$ del artículo 579 del CPC, sobre el embargo y secuestro de bienes propios del cónyuge o compañero permanente y se precisa en el artículo 480 numeral $3^{\circ}$, que no se podrán embargar o secuestrar, que el juez debe abstenerse de practicar las medidas, pero que si se realizan, los interesados estos pueden levantarlas promoviendo un incidente para ello.

Se aclara que para el embargo y secuestro se tendrán en cuenta las reglas generales y las especiales contenidas en el artículo 480, en los numerales $1^{\circ}$ a $5^{\circ}$ (que corresponden a los parágrafos $1^{\circ}$ y $2^{\circ}$ del artículo 686 del CPC).

Con todo, se mantiene en el artículo 496, numeral $3^{\circ}$, la previsión existente hoy en el artículo 595 del CPC, del decreto del secuestro de los bienes en caso de desacuerdo en la administración entre los herederos, entre estos y el cónyuge o compañero permanente (que se agrega) o entre cualquiera de los anteriores y el albacea.

Las posibilidades de secuestro definitivo que trae el 595 del CPC han generado dificultades en la práctica, por cuanto lo autoriza en caso de desacuerdo en la administración de los bienes entre el cónyuge y los herederos, 
o discordia entre el cónyuge y el albacea con tenencia de bienes. En cambio las diferencias en cuanto a la administración entre estas personas, se deciden de plano si no hay pruebas para practicar y mediante incidente en caso contrario, pero no se autoriza el secuestro, así, resulta difícil determinar cuándo se trata de un desacuerdo, una discordia o una diferencia para ver si procede o no el secuestro. Igual indeterminación, infortunadamente, quedó en el artículo 496 del CGP.

\subsection{ArtíCulo 482. Herencia yaCente.}

El artículo 581 del CPC establece que el auto que rechace la solicitud de declaración de yacencia de la herencia es apelable. El artículo 482 del CGP suprime la apelación y aumenta al compañero permanente como sujeto con interés para presentar la solicitud.

Se mejora la redacción del trámite de la solicitud contemplado en el artículo 582 del CPC al establecer en el numeral $1^{\circ}$ el artículo 483 del CGP que el emplazamiento se hará en la forma prevista en el código y que si existiere testamento se ordenará, además, la notificación personal o en su defecto el emplazamiento de los herederos y legatarios. En el numeral $3^{\circ}$ se cambia el nombre de curador por el de administrador de la herencia, por cuanto la Ley 1306 de 2009 cambió el nombre de los curadores de bienes por el de administradores de bienes.

El numeral $6^{\circ}$ del citado artículo 483 dice que cuando el juez venda los bienes, el valor se consignará a órdenes del Consejo Superior de la Judicatura y no a órdenes del juzgado como lo contempla hoy el artículo 582, numeral $4^{\circ}$, inciso $2^{\circ}$ del CPC. Además, agrega esta norma que el juez lo invertirá en títulos de crédito de la nación y/o los depositará en la sección fiduciaria de un banco o entidad similar, lo cual se suprime.

Igualmente, este artículo estatuye que el remate se hará de acuerdo con lo dispuesto para el remate de bienes en el proceso de sucesión y el nuevo artículo 483 dice que se hará de acuerdo con lo previsto para el remate en el proceso divisorio, esto obedece a que el actual artículo 617 sobre el remate de bienes en la sucesión remite al divisorio, por ello el 483 señala directamente el trámite del divisorio para el remate.

El artículo 582 del CPC prescribe que los acreedores pueden pedir que les reconozcan los créditos y el juez decidirá por auto apelable. El artículo 483 no contempla el recurso de apelación para la decisión y, por tanto, queda solo el recurso de reposición.

Por último, el artículo 582 del CPC prevé en el numeral $8^{\circ}$ que el curador pueda entregar los muebles y dineros a los legatarios con autorización del juez 
mediante auto apelable en el efecto diferido, el 483 mantiene esta facultad para el administrador, en el numeral $8^{\circ}$, pero le quita el recurso de apelación al auto que decida la solicitud de administrador.

\subsection{ARTíCulO 486. DECLARACIÓN DE VACANCIA DE LA HERENCIA.}

Actualmente, el artículo 584 del CPC establece que transcurridos veinte años desde el fallecimiento del causante, sin que se presenten herederos que reclamen la herencia, el juez de oficio, o a solicitud de parte, la declarará vacante y dará a los títulos el destino previsto en el artículo 582, numeral $4^{\circ}$. El nuevo artículo 486 reduce el término a diez años, para hacerlo compatible con lo prescrito en la Ley 791 de 2002, que redujo los términos de prescripción de veinte a diez años, asimismo, dispone que a los dineros se les dará el destino señalado en el artículo 483, es decir, que se consignarán a órdenes del Consejo Superior de la Judicatura.

\section{TRÁMITE DEL PROCESO DE SUCESIÓN.}

\subsection{Artículo 487. Disposiciones PRELIMINARES.}

Con el artículo 487 se mejora la redacción y el contenido del artículo 586 del $\mathrm{CPC}$, en cuanto establece que por el procedimiento para el trámite del proceso de sucesión se liquidarán las sucesiones testadas, intestadas o mixtas, sin perjuicio del trámite notarial previsto por la ley. De igual forma, suprime la referencia que hace el artículo 586 al Decreto 902 de 1988.

Contempla también que se liquidarán en el mismo proceso las sociedades conyugales y patrimoniales disueltas por cualquier causa antes de la muerte del causante, las que estén pendientes de liquidación al momento de la muerte y las disueltas por su fallecimiento. Con ello, se supera la discusión actual en torno a si una sociedad disuelta antes de la muerte y pendiente de liquidación al momento del deceso debe tramitarse en el proceso de sucesión, si debe hacerse en el proceso de liquidación o, en caso de que este ya esté en curso, si debe darse por terminado para efectuar la liquidación en el proceso de sucesión. Hay casos en los que se han adelantado los dos trámites liquidatorios por estar en curso el de liquidación de la sociedad conyugal antes de la muerte del cónyuge.

La referencia a los compañeros permanentes es obvia, dado que la Ley 54 de 1990 dispuso que la muerte de uno o ambos compañeros disuelve la sociedad patrimonial y que esta se liquidará en el proceso de sucesión, siempre que esté la prueba de su existencia y disolución. La Corte Constitucional aplicó a 
los compañeros del mismo sexo los efectos de la Ley 54, mediante la Sentencia C-577 de 2011.

Igualmente, la Corte Constitucional les reconoció derecho a porción conyugal y vocación hereditaria a los compañeros permanentes mediante las sentencias C-283 del 13 de abril de 2011, M.P: Jorge Ignacio Pretelt Chaljub y C-238 del 22 de marzo del 2012, M.P: Gabriel Eduardo Mendoza Martelo, aún a los del mismo sexo.

De otro lado, el artículo 487, parágrafo, consagra una institución novedosa en la legislación colombiana que es la partición patrimonial en vida, a la cual se le dedicará un espacio más adelante.

\subsection{Artículo 488. CONTENido de LA DEMANDA.}

En el artículo 488 se suprimen los numerales $3^{\circ}$ y $4^{\circ}$ y el inciso $2^{\circ}$ del numeral $5^{\circ}$ del artículo 587, sobre contenido de la demanda de sucesión, que decían:

3. Una relación de los bienes de que se tenga conocimiento, relictos o que formen el haber de la sociedad conyugal.

4. Una relación del pasivo que grave la herencia y del que exista a cargo de la sociedad conyugal.

5. (....). La demanda presentada por un asignatario a título singular implica la aceptación del legado; la del albacea, la de su cargo. En ambos casos, la petición de medidas cautelares implica su aceptación.

En lo demás, la disposición conserva el contenido del código anterior.

Sin embargo, se establece un requisito especial que es la obligatoriedad de indicar el nombre y la dirección de los herederos conocidos, ya que el nuevo procedimiento se hizo más coercitivo para los herederos en la medida en que su incomparecencia les acarrea severas consecuencias patrimoniales.

Igualmente, debe indicarse la dirección del cónyuge o compañero permanente, a quien también debe notificarse personalmente, para que opten por porción conyugal o marital o por gananciales.

\subsection{Artículo 489. ANeXos de LA DEMANDA.}

Con el artículo 489 se sustituyó el 588 del código anterior, sobre anexos de la demanda; se modifica el numeral $4^{\circ}$ de esta manera: "La prueba de la existencia del matrimonio, de la unión marital o de la sociedad patrimonial reconocida si el demandante fuere el cónyuge o el compañero permanente".

Si bien la sociedad patrimonial se liquida en el proceso de sucesión, para ello se requiere que la misma esté declarada y disuelta, de ahí que se exija la prueba 
como un requisito de la demanda, la cual ha de ser la sentencia judicial, el acta de conciliación o la escritura pública (L. 979/2005), donde consta la declaración y disolución, con la constancia de inscripción en el registro civil, por tratarse de un estado civil ${ }^{11}$. Así lo exige expresamente el numeral $8^{\circ}$ del artículo 489 del CGP.

Se sustituye el numeral $5^{\circ}$ por el siguiente numeral del 489 del CGP, "5.Un inventario de los bienes relictos y de las deudas de la herencia, y de los bienes, deudas y compensaciones que correspondan a la sociedad conyugal o patrimonial, junto con las pruebas que se tengan sobre ellos". De igual forma, se aumenta el numeral $6^{\circ}$ : "Un avalúo de los bienes relictos de acuerdo con el artículo 444".

El inventario no tiene mayor relevancia práctica; en realidad tenía mucha, sobre todo en las propuestas iniciales de reforma, cuando se establecía que los herederos o el cónyuge o compañero permanente podían objetar el inventario dentro de los diez días siguientes a la notificación de auto de apertura. Así aparece en el acta No. 53 de la Comisión Redactora del Código General del Proceso. En el nuevo código el inventario y el valor de los bienes no son vinculantes, ni siquiera para fijar la cuantía, porque esta, según el artículo 26, numeral $5^{\circ}$, se establece por el valor de los bienes relictos, que en el caso de los inmuebles será el avalúo catastral. La importancia de la exigencia de este anexo radica en que los interesados se vayan enterando de qué bienes y deudas se relacionarán en el inventario para que se provean de las pruebas necesarias para una posible objeción.

El numeral $6^{\circ}$ indica que ya no basta con la exigencia del código anterior, de hacer una relación de bienes y de deudas, sino que hay que elaborar un verdadero inventario y avalúo y aportarlo con la demanda. El avalúo debe ceñirse a lo previsto en el artículo 444 del CGP. Esto es, que al tratarse de inmuebles, el valor es el del avalúo catastral aumentado en un cincuenta por ciento, salvo que quien lo aporte considere que ese valor no es el real, caso en el cual debe presentar dictamen pericial practicado por entidades o profesionales especializados. Para los vehículos automotores, el valor será el fijado oficialmente para calcular el impuesto de rodamiento, igualmente aumentado en un cincuenta por ciento o se debe adjuntar un dictamen practicado, como en el caso de los inmuebles, o puede ser el valor señalado por revistas especia-

11 COLOMBIA. Corte Suprema de Justicia. Auto del 10 de noviembre del año 2004, CSJ., M.P.: Carlos Ignacio Jaramillo Jaramillo; auto del 18 de junio del 2008, CSJ., M.P.: Jaime Arrubla Paucar; sentencia del 11 de marzo de 2009, M.P.: William Namén Vargas. Debiéndose por tanto inscribir en el registro civil, así sea en el libro de Varios, artículo 22 Decreto 1260 de 1970 y $1^{\circ}$ del Decreto 2158 de 1970. 
lizadas (agrego, como la Motor o la de Fasecolda), acompañado por la página correspondiente.

Esto es importante, porque si los interesados no presentan las pruebas sobre el valor de los bienes, en esta oportunidad o en la señalada en el numeral $3^{\circ}$ del artículo 501, el juez promedia los valores que les hayan asignado los interesados.

\subsection{Artículo 490. Apertura del proceso de SuCESión.}

El artículo 490 sobre apertura del proceso de sucesión, con el cual se sustituye el 589 del CPC, también hace importantes modificaciones. En primer lugar, dispone que declarada la apertura del proceso el juez ordenará notificar a los herederos conocidos y al cónyuge o compañero permanente para los fines previstos en el artículo 492, esto es, con consecuencias de repudiación de la herencia y de renuncia a la impugnación de la partición con posteridad a la ejecutoria de la sentencia.

Igualmente, se dispone que si en la demanda no se señalan herederos conocidos, se citará al Instituto Colombiano de Bienestar Familiar o a las entidades que tengan vocación legal, y que, en todo caso, se ordenará informar a la Dirección de Impuestos y Aduanas Nacionales. Se ordena emplazar a las demás personas que se crean con derecho a intervenir en el proceso de sucesión, en la forma prevista en el código. Es decir, según el artículo 108 del CGP.

Dado que en los lugares apartados las personas tienen como medio de información favorito, y a veces único, la radiodifusión, el juez, según las circunstancias, puede ordenar la publicación de la apertura en una radiodifusora de la localidad o región del último domicilio del causante. Se dispone asimismo que el Consejo Superior de la Judicatura llevará el Registro Nacional de Apertura de Procesos de Sucesión, en la página WEB de la Rama Judicial.

La citada disposición prevé también en su parágrafo $3^{\circ}$ que si en el curso del proceso aparece un heredero o cónyuge o compañero, debe notificársele personalmente o por aviso, y que si es niño, niña o adolescente o incapaz, se le notificará al representante legal o a un curador ad litem.

Es importante señalar que, en la legislación actual, el auto que niegue la apertura del proceso de sucesión es apelable en el efecto suspensivo, y el que lo declare abierto en el efecto devolutivo (art. 589 inc. $3^{\circ}$ ), mientras que en el CGP, solo se dice que es apelable el que niegue la apertura (art. 490 inc. $2^{\circ}$ ). Pese a que no se haya dicho expresamente en este artículo cuál es el efecto del recurso en caso de que se niegue la apertura, debe ser en el suspensivo, pues no hay providencia alguna que cumplir o cuyo cumplimiento deba ser diferido. Sin embargo, debe tenerse en cuenta lo dispuesto en el numeral $7^{\circ}$ del artículo 
491, en cuanto dispone que el auto que resuelve sobre el reconocimiento de interesados o decide el incidente de heredero de mejor derecho sea apelable en el efecto diferido, pero si además se pronuncia sobre la apertura del proceso, el efecto será el devolutivo.

\subsection{ARtíCULO 491. RECONOCIMIENTO DE INTERESADOS.}

Según el artículo 590 numeral $3^{\circ}$ del CPC, hasta antes de proferirse sentencia aprobatoria de la partición, se pueden reconocer herederos o legatarios, al cónyuge sobreviviente o al albacea. El artículo 490 del CGP, numeral 3º establece que se pueden reconocer, incluido el compañero permanente hasta antes de la ejecutoria de la sentencia aprobatoria de la última partición o adjudicación.

Los interesados que acudan al proceso después de su apertura lo tomarán en el estado en que se encuentre.

\subsection{ARTÍCULO 492. REQUERIMIENTO A HEREDERO PARA EJERCER EL DERECHO DE OPCIÓN, Y AL CÓNYUGE O COMPAÑERO SOBREVIVIENTE. REPUDIACIÓN POR INCAPACES Y AUSENTES.}

En realidad, el título que en últimas quedó para el artículo 492 surgió en el último debate en plenaria del Senado, porque hasta el proyecto presentado al cuarto debate, el título era: "Requerimiento para aceptar la herencia". El derecho de opción es del cónyuge o del compañero permanente entre porción conyugal o marital o gananciales. Pero ahora debe pensarse que también es del heredero entre la aceptación de la herencia y la repudiación de la misma.

Se reduce el término previsto en el artículo 1289 del Código Civil de 40 días a 20 para aceptar o repudiar la asignación, pero el término es prorrogable por otro período igual. El artículo 1289 del CC permitía la prórroga hasta por un año.

La notificación del auto de apertura del proceso surte los efectos de requerimiento (CGP, art. 490 inc. $1^{\circ}$ y 94 inc. $3^{\circ}$ ).

Como lo dispone hoy el artículo 591 del CPC, en el artículo 492 del CGP se consagra que

"Si se ignora el paradero del asignatario, del cónyuge o compañero permanente y estos carecen de representante o apoderado, se les emplazará en la forma indicada en este código. Surtido el emplazamiento, si no hubiere comparecido, se le nombrará curador, a quien se le hará el requerimiento para los fines indicados en los incisos anteriores, según corresponda. El curador representará al ausente en el proceso hasta su apersonamiento y, en el caso de 
los asignatarios, podrá pedirle al juez que lo autorice para repudiar. El curador del cónyuge o compañero permanente procederá en la forma prevista en el artículo 495. Los asignatarios que hubieren sido notificados personalmente o por aviso de la apertura del proceso de sucesión, y no comparezcan, se presumirá que repudian la herencia, según lo previsto en el artículo 1290 del Código Civil”.

La sanción de presunción de repudiación de la herencia no se aplica sino a quienes fueron notificados personalmente o por aviso de la apertura del proceso de sucesión.

Cuando se notifica al curador ad litem, este debe pedirle autorización al juez para repudiar, toda vez que para la repudiación se necesita plena capacidad. El artículo 1293 del CC, consagra que "los que no tienen la libre administración de sus bienes no pueden repudiar una asignación a título universal, o una asignación de bienes raíces o bienes muebles que valgan más de mil pesos, sin autorización judicial con conocimiento de causa".

Por su parte el artículo 593 del CPC dispone que el juez solo puede autorizar una repudiación de la asignación a favor de un incapaz o de un ausente, si se demuestra que la aceptación puede causarle perjuicio.

La Ley 1306 de 2009, sobre discapacidad, preceptúa en el artículo 92 literal a) que no será lícito al curador "dejar de aceptar actos gratuitos desinteresados en favor del pupilo", y el 93 ibídem trae los actos del curador en los que se requiere autorización judicial, en el literal e) dice: "El repudio de los actos gratuitos interesados o modales en favor del pupilo. Las herencias podrán ser aceptadas libremente, pero se presumirá de derecho que han sido aceptadas con beneficio de inventario". El contenido de estas normas reemplaza lo que estaba previsto en los artículos 486 y 575 del CC, derogadas con la Ley 1306, en lo que tiene que ver con la repudiación por parte de los curadores de bienes del ausente, de los derechos eventuales del que está por nacer y de la herencia yacente.

En el artículo 494 del CGP desaparece el inciso primero del artículo 591, relacionado con la única causa por la que el juez puede aceptar la repudiación de una asignación hecha a un incapaz. Dice la norma: "La solicitud de autorización para repudiar asignaciones a favor de incapaces o ausentes se tramitará como incidente, con intervención del Ministerio Público y el defensor de familia. El auto que lo decida es apelable en el efecto diferido"; luego, el inciso $2^{\circ}$ del artículo 591 se convierte en el contenido del nuevo artículo 494 y agrega que en el incidente debe intervenir además el defensor de familia.

Desaparece de la norma original (art. 591) el único caso de autorización para la repudiación de una asignación al ausente, que es cuando esta le causa perjuicio. Sin embargo, queda comprendido dentro de la autorización judicial 
requerida en el literal e del artículo 93 de la Ley 1306 para los curadores, y en el parágrafo 4 del artículo 492 del CGP, para que el curador ad litem pueda repudiar, consistente en que el juez debe autorizar el repudio de los actos gratuitos interesados o modales en favor del pupilo, mientras que las herencias podrán ser aceptadas libremente, pero se presumirá de derecho que han sido aceptadas con beneficio de inventario.

\subsection{CONSECUENCIAS DEL SILENCIO DEL CÓNYUGE O COMPANERO PERMANENTE.}

El cónyuge o compañero permanente también deben ser requeridos. $\mathrm{Si}$ comparecen como herederos, se aplican las consecuencias de la repudiación e imposibilidad de impugnar posteriormente la partición. Lo anterior, por cuanto los cónyuges o compañeros pueden acudir al proceso a reclamar sus gananciales, porción conyugal o la herencia. Cuando acuden con estas dos últimas calidades, son asignatarios. La consecuencia del silencio de los asignatarios requeridos es, en principio, la repudiación de la asignación y la inimpugnabilidad de la partición (art. 492, inc. $5^{\circ}$ ).

Pese a lo anterior, el artículo 495 prescribe que si el cónyuge guarda silencio, se entiende que opta por gananciales y que si no tiene derecho a estos, se entenderá que eligió porción conyugal; además, el artículo 492, en su inciso $2^{\circ}$, reza que el requerimiento al cónyuge o compañero tiene como objeto que opte por gananciales o porción. De manera que si la ley le atribuye al silencio del cónyuge o compañero la consecuencia de que se entiende que opta por gananciales, no puede aplicarse otra diferente.

Sobre este aspecto se pronunció la Sala Civil de la Corte Suprema, en el sentido de que no le son aplicables al cónyuge los artículos 591 del CPC y 1289 del CC. Sin embargo, considero que si es requerido como heredero, se le aplican las consecuencias señaladas.

\subsection{Artículo 492 inciso último. APERTURA del proceso DE SUCESIÓN POR UN ACREEDOR.}

Es bueno recordar que según el inciso final del artículo 492 del CGP, cuando el proceso se inicia por un acreedor, si dentro de los dos meses después del emplazamiento no se han presentado herederos o el Instituto Colombiano de Bienestar Familiar a aceptar la herencia, el juez da por terminado el proceso, salvo que se haya presentado el cónyuge o el compañero permanente a ejercer su derecho. Como se verá el acreedor no tiene legitimación para elaborar el inventario por no ser comunero. 


\section{INVENTARIO Y AVALÚOS.}

Se trasladan los artículos 600 y 601 del CPC al 501 del CGP y no hay variación importante en cuanto a la confección del inventario.

La gran modificación contenida en este artículo a los artículos 600 y 601 del código anterior es en cuanto a la objeción al inventario. Hoy, existe una gran discusión en torno a si el inventario puede objetarse dentro del término de traslado por el valor de los bienes y por el pasivo, o si por el valor de los bienes y por el pasivo, solo es posible objetar el inventario en la audiencia de confección del mismo. Se discute, igualmente, si el juez tiene que abrir un espacio procesal para que se demuestre la naturaleza social o propia de una deuda que ha sido objetada durante la audiencia.

Como lo establece el artículo 600 del CPC, el inventario es confeccionado por los interesados, esto es, las personas relacionadas en el artículo 1312 del $\mathrm{CC}$, pero su interés no es el mismo. Los únicos que tienen un interés pleno son los comuneros universales, es decir, los herederos, el cónyuge o el compañero permanente, que son los que pueden relacionar los bienes, las deudas y las recompensas. Los demás como los acreedores, el albacea, los legatarios y los fideicomisarios tienen un interés limitado a su derecho e intervienen para hacerlo reconocer, si no hay comuneros no puede confeccionarse el inventario.

Los bienes del activo deben ser valorados cada uno por separado, porque el partidor no puede distribuir sino un solo valor. De ahí que los comuneros deban estar de acuerdo con el valor, de lo contrario, el juez nombra perito para que los valore. El juez, en este caso, no corre traslado del inventario mientras no sea presentado el dictamen o dictámenes sobre el valor de los bienes para correr traslado conjunto, tanto de este o estos y del inventario, a efecto de que la contradicción del dictamen y la objeción al inventario se resuelvan en un mismo incidente. Algunos jueces y tribunales consideran que si el desacuerdo no se presenta en la audiencia en el momento de relacionar el valor de los bienes, precluye la oportunidad para objetarlo en el término de traslado. Otros consideran que una partida mal valorada está indebidamente incluida y que por tanto es oportuna la objeción en dicho término.

Algo similar acontece con los pasivos. Prescribe el artículo 600 del CPC que en el pasivo irán las obligaciones que los interesados (comuneros) acepten de común acuerdo. Aquellas obligaciones que consten en título ejecutivo, siempre que no sean objetadas y que los créditos de los acreedores no fueren inventariados, podrán hacerse valer en proceso separado, para lo cual, los documentos aportados serán inmediatamente devueltos. Es más, algunos tratadistas consideran que si son objetados "el juez que conoce de la sucesión no tiene 
competencia para dirimir dentro del mismo si existe o no razón en la censura, motivo por el cual no se podrían inventariar ${ }^{12}$.

Igualmente, la misma disposición contempla que quienes no asistan a la audiencia aceptan las deudas que los demás relacionen.

Por el contrario, otros consideramos que si son terceros acreedores los que se presentan a pedir el reconocimiento de su crédito y es objetado el mismo, no puede tramitarse en el mismo proceso la objeción porque los acreedores cuentan con las acciones judiciales pertinentes para hacer valer su créditos, de ahí que los documentos aportados deban ser devueltos en la misma audiencia para respaldar sus créditos.

Pero cosa diferente ocurre cuando los créditos son incluidos en el inventario o cuando algún interesado no asiste a la diligencia. Creo que debe admitirse la objeción en el término de traslado para que se establezca si la deuda realmente existe o no, total o parcialmente, o si existió y se extinguió por algún modo, o si es social o propia, en virtud de que todas estas controversias tienen que ver con que la deuda esté o no bien incluida en el inventario. Este puede ser objetado para que se excluyan partidas indebidamente incluidas o se incluyan recompensas (CPC, art. 601).

Aún en el caso de que los comuneros no asistan al inventario, pueden impugnar el inventario por el pasivo relacionado por los otros, porque la presunción de aceptación por la inasistencia es legal y puede ser desvirtuada a través de la oposición. La razón de la aceptación tácita es la de completar el negocio jurídico sustancial del inventario con el consentimiento provisional de los ausentes. Adicionalmente, el inciso $2^{\circ}$ del artículo 1312 del CC prevé que cualquier interesado de los relacionados en ese artículo puede reclamar contra el inventario en lo que le pareciere inexacto. No podía ser de otra manera si el proceso de sucesión lo que busca es determinar el patrimonio real del causante y su distribución entre sus herederos, previas las deducciones previstas en la ley.

El CGP trata de superar esas discusiones y señala una nueva forma de objetar el inventario y de resolver las objeciones.

En el numeral $1^{\circ}$ del artículo 501 , incisos $4^{\circ}$ y $7^{\circ}$, se dispuso que las objeciones a las deudas sociales y a las denunciadas por los acreedores se decidirán como lo dispone el numeral $3^{\circ} \mathrm{y}$, al finalizar el último inciso del numeral $2^{\circ}$, se señala: "Todas las objeciones se decidirán en la continuación de la audiencia mediante auto apelable".

12 LÓPEZ BLANCO, Hernán Fabio. Instituciones de Derecho Procesal Civil Colombiana.

T. II, Parte Especial, Quinta Edición. p. 562. 
Pues bien, el numeral $3^{\circ}$ consagra la forma de decidir las objeciones, de la siguiente manera:

3. Para resolver las controversias sobre objeciones relacionadas con los inventarios y avalúos o sobre la inclusión o exclusión de bienes o deudas sociales, el juez suspenderá la audiencia y ordenará la práctica de las pruebas que las partes soliciten y las que de oficio considere, las cuales se practicarán en su continuación. En la misma decisión señalará fecha y hora para continuar la audiencia y advertirá a las partes que deben presentar las pruebas documentales y los dictámenes sobre el valor de los bienes, con antelación no inferior a cinco (5) días a la fecha señalada para reanudar la audiencia, término durante el cual se mantendrán en secretaría a disposición de las partes.

En la continuación de la audiencia se oirá a los testigos y a los peritos que hayan sido citados, y el juez resolverá de acuerdo con las pruebas aportadas y practicadas. Si no se presentan los avalúos en la oportunidad señalada en el inciso anterior, el juez promediará los valores que hubieren sido estimados por los interesados, sin que excedan el doble del avalúo catastral.

Hoy no queda duda entonces de que el CGP permite el trámite de la objeción por el valor y por el pasivo y que deben tramitarse las objeciones y decidirse, como lo dispone esta norma, todo dentro de la audiencia.

El inventario es elaborado de común acuerdo por los interesados pero debe ser presentado por escrito en la audiencia. Aunque la norma dice que deben elaborarlo de común acuerdo, es posible que no lo estén, y por este motivo no podrán prescindir de su confección. Para ello están previstas las objeciones. No se previó traslado del inventario pero igual el juez debe dar traslado para que en la misma audiencia los interesados lo objeten si no están de acuerdo con él. Si esto sucede, se suspende y a continuación se practican las pruebas y se deciden las objeciones con auto apelable. En el auto de suspensión se requiere a los interesados para que, por lo menos con cinco días de antelación a la fecha de la continuación de la audiencia, aporten los dictámenes sobre el valor de los bienes, si no los presentan, el juez promediará los valores que hubiesen sido estimados por aquellos, sin que excedan el doble del avalúo catastral.

De acuerdo con el artículo 507 del CGP, aprobado el inventario y avalúo, el juez en la misma audiencia decretará la partición. Ya no tiene que esperar, como ahora, a que los interesados le pidan la partición con el argumento de que no puede decretarla de oficio. Debe recodarse que el artículo 953 del Código Judicial, Ley 105 de 1931, consagraba que "Aprobados el inventario y avalúo, y en su caso, el decreto de posesión efectiva, cualquiera de los herederos, con las limitaciones prescritas en el artículo 1379 del Código Civil, puede pedir que se 
haga la partición, expresando en la demanda el nombre y domicilio de cada uno de los coherederos. La licencia para pedir la partición, en el caso prescrito en dicho artículo, puede darla el mismo Juez de la causa".

De otra parte, el artículo 954 establecía: "De la demanda de partición se corre traslado común de tres días a las partes. Si alguna se opone, se decide el punto mediante una articulación".

A partir del Código de Procedimiento Civil de 1970, aprobado el inventario, inmediatamente se puede pedir la partición sin ninguna formalidad. En su momento la reforma constituyó un gran avance toda vez que suprimió la demanda de partición y el traslado.

El inciso primero del artículo 507 del CGP establece que "En la demanda de apertura del proceso de sucesión se entiende incluida la solicitud de partición, siempre que esté legitimado para pedirla quien lo haya promovido". Además, el inciso tercero consagra que "El auto que decrete la partición lleva implícita la autorización judicial para realizarla si hubiere incapaces, caso en el cual el juez designará el partidor". Actualmente según el artículo 608 del CPC, no solo debe pedirse la partición sino también el decreto de autorización para hacer la partición si hay incapaces. Esto último, en concordancia con lo previsto en el artículo 1379 del CC, que contempla la necesidad de la autorización judicial al partidor para hacer la partición si hay incapaces. Según la doctrina, la falta de autorización judicial afecta de nulidad relativa sustancial la partición.

Igualmente, el mismo auto de decreto de la partición designa al partidor, si los interesados no lo hubieren hecho (CGP, art. 507).

\subsection{INVENTARIO Y AVALÚOS ADICIONALES.}

El artículo 502 señala que si se hubiere dejado de inventariar bienes, podrá presentarse inventario y avalúos adicionales, del cual se correrá traslado por tres (3) días. Si no se presentan objeciones, el juez aprobará el inventario, y si se presentan, serán resueltas en audiencia que se celebrará dentro de los cinco (5) días siguientes al vencimiento del traslado.

Nada dijo la norma sobre el traslado de las objeciones a los interesados, creo que aunque no lo haya dicho la norma tendrá que hacerse antes de fijar fecha y hora para la audiencia porque los demás interesados deben conocer las objeciones para poder ejercer su derecho de contradicción, de lo contrario, se presentarían a la audiencia sin posibilidad de defensa. Decididas las objeciones en el mismo auto y dentro de la misma audiencia, se aprueba el inventario adicional.

El CGP no se pronunció sobre la apelabilidad del auto que decide las objeciones al inventario y avalúos adicionales y tampoco está en el listado de las 
providencias apelables del artículo 321. Sin embargo, como se trata del auto que decide objeciones, si las hay, sería apelable, como acontece con el que decide las objeciones al inventario principal (art. 501, num. $2^{\circ}$, último inc.).

Llama la atención el inciso $2^{\circ}$ del artículo 502, en cuanto preceptúa que "Si el proceso se encuentra terminado, el auto que ordene el traslado [del inventario adicional] se notificará por aviso", dado que si el proceso está terminado ya no procede inventario adicional, sino partición adicional sujeta al trámite descrito en el artículo 518 del CGP.

El cambio en la elaboración del inventario adicional es fundamental, porque actualmente se le aplica la norma del inventario principal al adicional (CPC, art. 600, num. $4^{\circ}$ ), por lo que la confección, traslado, objeciones, decisiones y recursos, se rigen por lo dispuesto para el inventario principal.

\section{POSESIÓN EFECTIVA DE LA HERENCIA.}

El CGP, en el artículo 626, literal c), derogó los numerales $1^{\circ}$ y $2^{\circ}$ del artículo 757 y el inciso final del artículo 766 del CC sobre la posesión efectiva de la herencia y no reprodujo el artículo 607 del CPC que prevé la posibilidad de que, aprobado el inventario y los avalúos de los bienes, cualquier heredero pueda pedirle al juez que expida a favor de todos los herederos el decreto de posesión efectiva de la herencia, conforme a lo prevenido en el artículo 757 del CC, y que ordene su inscripción en la oficina de registro de instrumentos públicos.

Según el artículo 757, dicho decreto le da a los herederos la facultad de disponer de los bienes inmuebles como cuerpo cierto. En verdad, los herederos poseedores efectivos de la herencia, pese a que se inscriba el decreto, no pueden transferir el dominio porque la posesión efectiva no es modo de adquirir la propiedad en Colombia y, por lo tanto, no adquieren el derecho de dominio sobre los bienes inmuebles inventariados ${ }^{13}$. De ahí que aparte de darle publicidad a la sucesión y de servir de justo título para adquirir el dominio por el modo de la prescripción ordinaria (CC, art. 766, inc. final, que también se deroga), no surta un efecto práctico ese decreto.

En el Código Judicial de 1931 (L. 105/1931), se establecía en el artículo 968 que "si no hay más que un solo heredero, a este le basta para disponer de los bienes herenciales, el decreto de posesión efectiva de la herencia". Por ello, la Corte Suprema de Justicia decía que cuando hay un solo heredero, el decreto de

13 Casación 6 de marzo de marzo de 1944, LVII, 18, y casación del 3 de junio de 1960, Gaceta Judicial t. XCII. p. 909. (Citada por ÁLVAREZ GÓMEZ, Marco Antonio. Ensayos sobre el Código General del Proceso. Colección Debates, Volumen I. Universidad Javeriana). 
posesión efectiva de la herencia hace las veces de adjudicación ${ }^{14}$. Esta norma no fue reproducida en el Código de Procedimiento Civil de 1970.

Adicionalmente, la publicidad está garantizada por el CGP en el artículo 490 con el registro nacional de procesos de sucesión que debe ser llevado en la página WEB por el Consejo Superior de la Judicatura.

Con la derogatoria del artículo 766 inciso final, queda también derogada la última parte del artículo 1326, sobre el justo título de la prescripción ordinaria de la acción de petición de herencia, por lo cual, el justo título para dicha prescripción será la sentencia aprobatoria de la partición, como lo sostiene el maestro Arturo Valencia Zea ${ }^{15}$.

\section{REGLAS PARA EL PARTIDOR, TRASLADO DE LA PARTICIÓN, OBJECIONES, DECISIÓN Y APROBACIÓN DE LA PARTICIÓN.}

En lo demás, esto es, en cuanto a la presentación de la partición, las objeciones, el trámite y la aprobación de la partición se conserva, en esencia, el mismo trámite previsto en el Código de Procedimiento Civil.

\section{ARTíCULO 518. PARTICIÓN ADICIONAL.}

Se modifica ostensiblemente el artículo 620 del CPC, para hacer el trámite de la partición adicional compatible con el nuevo trámite del proceso de sucesión.

Si la solicitud de partición adicional no está suscrita por todos los interesados, se ordenará notificar por aviso a los demás y se correrá traslado por el término de diez días. El traslado actual es por tres días.

De la partición conocerá el mismo juez que conoció del proceso de sucesión sin necesidad de reparto. Se quitó la parte de la norma del artículo 620, que decía que, no obstante si la competencia fuere del municipal y el valor de los nuevos bienes excediera su competencia, esta corresponderá al juez civil del circuito. La supresión es acorde con el cambio normativo en la competencia en el proceso de sucesión, que ya no se alterará como lo establece actualmente el artículo 21 numeral $1^{\circ}$ del CPC por el avalúo definitivo de los bienes, porque esta norma no se reprodujo en el artículo 27 del CGP, que es la nueva disposición sobre conservación y alteración de la competencia. De manera que, si conoció del proceso un juez municipal o promiscuo municipal, será este el que conozca de la partición adicional, independientemente del valor de los nuevos bienes.

14 COLOMBIA, Corte Suprema de Justicia. Casación 9 de abril de 1940, XLVIII, 987.

15 VALENCIA ZEA, Arturo. Derecho Civil. Tomo VI, sucesiones. Temis, 1977. p. 390. 
En la solicitud se indicarán los nuevos bienes, si se objeta la relación, se fijará fecha y hora y se procederá como para el inventario principal (art. 501), en todo lo demás, se adelanta el trámite previsto para el proceso principal (arts. 505 a 517).

\section{ARTÍCULO 512. ENTREGA DE BIENES A LOS ADJUDICATARIOS.}

En el artículo 512 se conserva, en líneas generales, el contenido del artículo 614 del C PC, pero se hace la aclaración en el sentido de que si la entrega no se solicita en tiempo, se aplicará el artículo 308. Es decir, que se puede pedir en cualquier tiempo, pero en este caso, se deben notificar por aviso a los adjudicatarios.

Actualmente, se presentan dificultades cuando los bienes no han sido secuestrados y no se pide la entrega dentro del término de cinco días siguientes a la ejecutoria de la sentencia aprobatoria de la partición (CPC, art. 613). Algunos estiman que debe tramitarse proceso ordinario y otros que se debe acudir por analogía al artículo 335 del CPC. Si se pide la entrega dentro de los 60 días siguientes a la ejecutoria de la sentencia, se ordena por auto que se notifica por estado, de lo contrario, puede pedirse en cualquier tiempo, pero, en este caso, el auto que ordene la entrega se notificará dentro en la forma prevenida en los artículos 315 a 320 y 330 del CPC.

La remisión a las normas generales solucionará las dificultades interpretativas que actualmente existen.

\section{ARTÍCULO 516. SUSPENSIÓN DE LA PARTICIÓN.}

En el CPC, en el artículo 618 se prevé la suspensión de la partición, la cual debe presentarse antes de que se dicte sentencia que apruebe la partición o adjudicación, y, aunque la norma establece que terminados los respectivos procesos se reanudará el de sucesión y se tendrá en cuenta lo decidido en ellos, el asignatario debe tomar el proceso en el estado que se encuentre. El artículo 516 amplía el término para la suspensión hasta "la ejecutoria de la partición de la sentencia aprobatoria de la partición”, pero trae una novedosa previsión, consistente en que: "El asignatario cuyas pretensiones hubieren sido acogidas, podrá solicitar que se rehagan los inventarios". Esto permitirá que, si el asignatario no está conforme con el inventario, en relación con la manera como este se confeccionó (bienes relacionados, valores de los mismos, deudas, recompensas etc.), podría solicitar su repetición para intervenir en la elaboración. 


\section{ARTíCUlO 509. PROTOCOLIZACIÓN.}

El segundo inciso del numeral $7^{\circ}$ del artículo 509 establece que la partición y la sentencia que la aprueba serán protocolizadas en una notaría del lugar que el juez determine, de lo cual se dejará constancia en el expediente. Con ello, se supera la dificultad actual con el retiro del expediente y la incertidumbre acerca de la notaría en la cual fue protocolizada, que obstaculizaba el ejercicio de derechos derivados de la partición o el ejercicio de las acciones que pudieran ejercer los interesados.

\section{CASACIÓN.}

Infortunadamente, en el CGP, en el artículo 334, no quedó previsto el recurso extraordinario de casación contra las sentencias liquidatorias, lo cual impedirá, salvo por vía de tutela, que la Corte Suprema de Justicia, como tribunal de unificación de la jurisprudencia, pueda pronunciarse sobre esa importante materia.

Estas son a mi juicio, las más sobresalientes reformas introducidas en el proceso de sucesión. Espero que estos comentarios sean de alguna utilidad para los estudiosos del derecho procesal.

\section{REFERENCIAS}

ÁlVAREZ GÓMEZ, Marco Antonio. Libro Ensayos sobre el Código General del Proceso. Colección Debates, Volumen I. Universidad Javeriana.

LAFONT PIANETTA, Pedro. Derecho de Sucesiones. Tomo II. Librería Ediciones El profesional. 2013.

LÓPEZ BLANCO, Hernán Fabio, Instituciones de Derecho Procesal Civil Colombiano, T. II, Parte Especial, Quinta Edición.

PÉREZ LASALA, José Luis. Curso de Derecho Sucesorio. Ediciones Depalma, 1989.

VALENCIA ZEA, Arturo. Derecho Civil. Tomo VI, sucesiones. Temis, 1977.

ZOPINI, Andrea. "Las sucesiones en el Derecho Comparado", Sucesiones y Herencia. Colección Tendencias Contemporáneas del Derecho, No. 15. Editores Académicos, 2013.

\section{JURISPRUDENCIA}

Auto del 10 de noviembre del año 2004, CSJ., M.P.: Carlos Ignacio Jaramillo Jaramillo.

Auto del 18 de junio del 2008, CSJ. M.P.: Jaime Arrubla Paucar.

Casación 9 de abril de 1940, XLVIII, 987.

COLOMBIA. CONGRESO DE LA REPÚBLICA. Decreto 1260 de 1970 y $1^{\circ}$ del Decreto 2158 de 1970.

COLOMBIA. Código General del Proceso- Ley 1564 de 2012. Instituto Colombiano de Derecho Procesal. 2014.

Sentencia del 11 de marzo de 2009. M.P.: William Namén Vargas. 